\section{THE HIJACKED BRAIN}

Addiction is a devastating disease that alters the brain's circuitry, notably in young adults. But the changes need not be permanent: improved understanding of them will help in developing ways to lessen the burden. By Margaret Munro. See a Nature Video at go.nature.com/elgqkk.

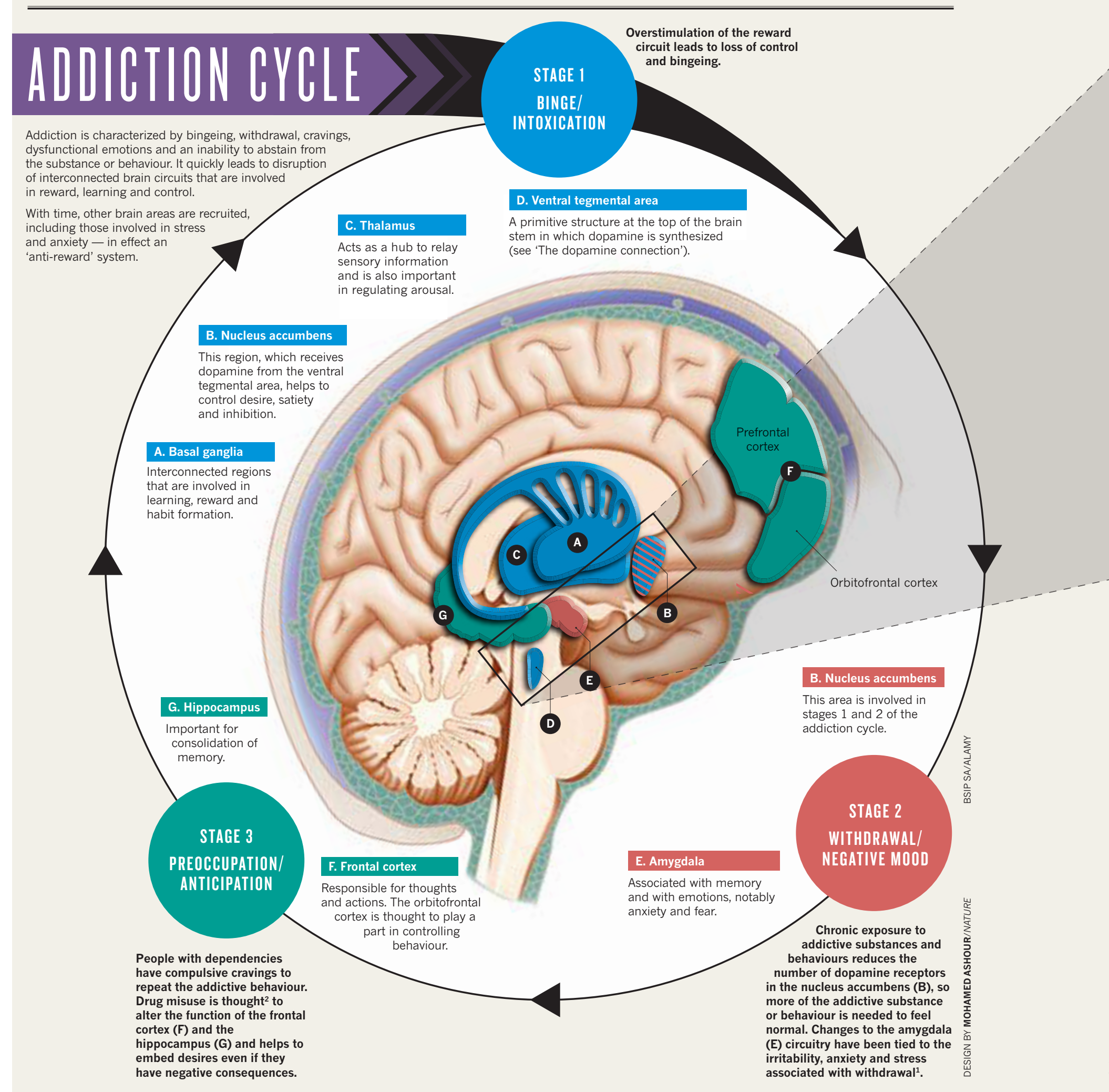

\begin{tabular}{|c|c|c|}
\hline 27 MULLON & |B|L|L|N & $38.3 \%$ \\
\hline $\begin{array}{l}\text { beople and problematic } \\
\text { drug use in } 20212 \text {. }\end{array}$ & 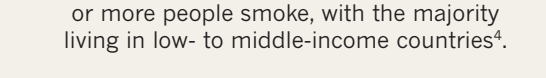 & 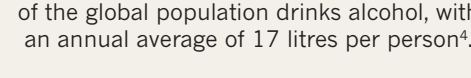 \\
\hline 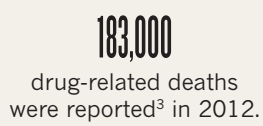 & 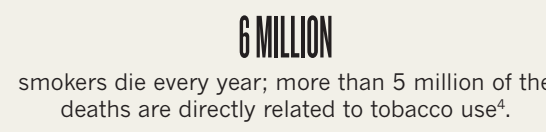 & 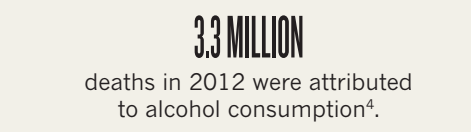 \\
\hline
\end{tabular}
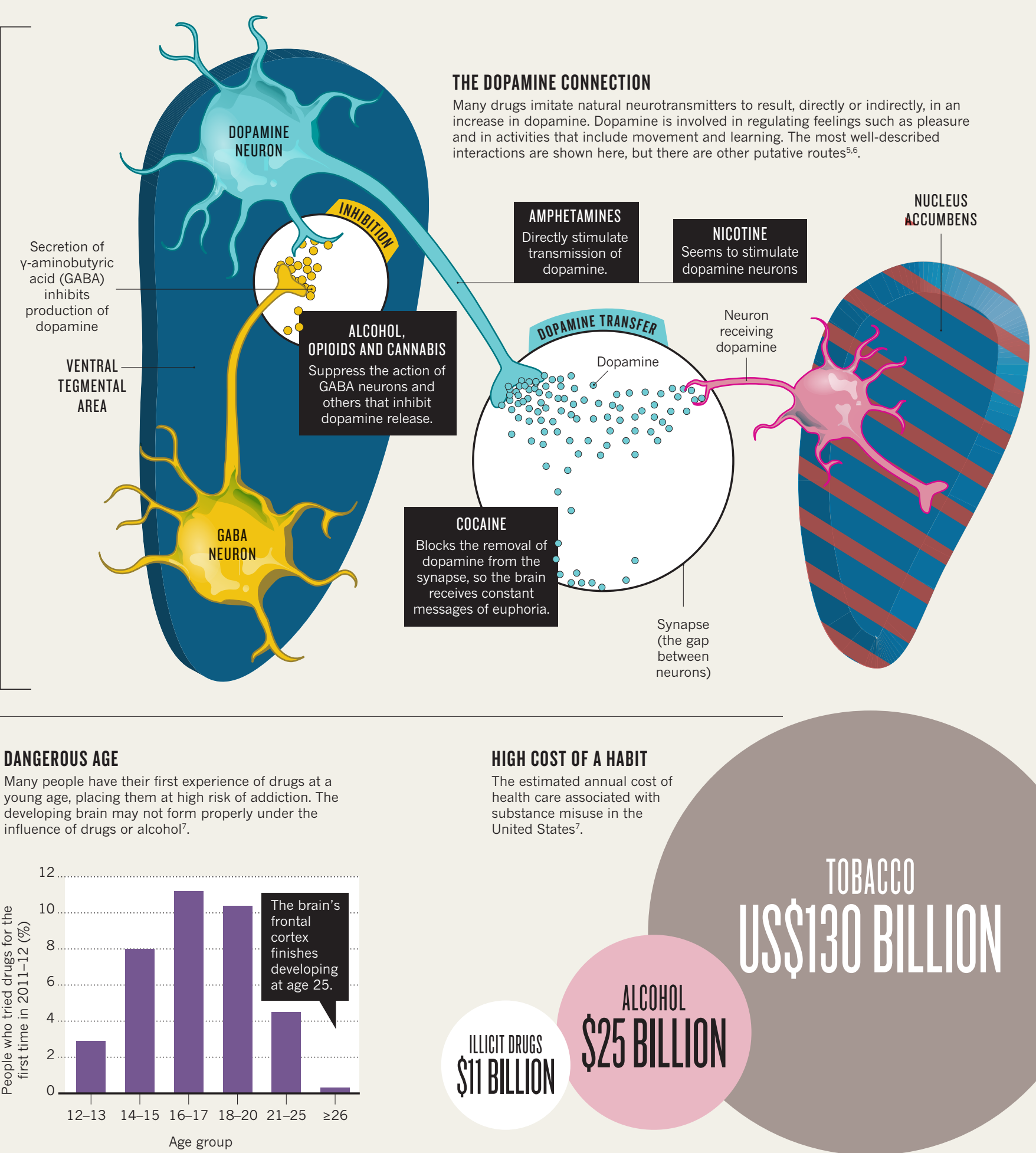

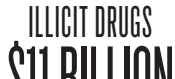

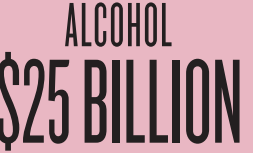

